\title{
dspace.vutbr.cz
}

\section{Energy conversion during effervescent atomization}

\author{
JEDELSKÝ, J.; JÍCHA, M.
}

Fuel

2013, vol. 111, September 2013, pp. 836-844

ISSN: 0016-2361

DOI: https://doi.org/10.1016/j.fuel.2013.03.053

Accepted manuscript

(C) 2013. This manuscript version is made available under the CC-BY-NC-ND 4.0 license

(http://creativecommons.org/licenses/by-nc-nd/4.0/), doi: https://doi.org/10.1016/j.fuel.2013.03.053

Final version available from https://www.sciencedirect.com/science/article/pii/S001623611300241X 


\title{
Energy Conversion during Effervescent Atomization
}

\author{
Jan Jedelsky*, Miroslav Jicha \\ Faculty of Mechanical Engineering, Brno University of Technology, \\ Technicka 2896/2, 61669 Brno, Czech Republic \\ jedelsky@fme.vutbr.cz and jicha@fme.vutbr.cz
}

\begin{abstract}
The paper qualitatively describes processes during the internal flow, discharge of twophase mixture as well as spray formation with a particular focus on the energy transfer during effervescent atomization of light heating oil. The near nozzle spray visualization elucidates the liquid breakup process at different operation modes. Numerical results illustrate the forms of energy involved in the atomization process, their values and the influence of operational conditions on relations between the energy forms. The main part of the paper focuses on the atomization efficiency. A simple method for estimation of the atomization efficiency of pneumatic atomizers is proposed; surface tension energy of created droplets, obtained from phase-Doppler anemometry data, is compared with the energy required for atomization. The atomization efficiency of effervescent atomizers is found to be in fragments of per cents for atomizing pressures ranging between 0.1 and $0.5 \mathrm{MPa}$, and gas-to-liquid ratios (GLRs) between 0.02 and 0.1 , and it is inferior, by about one order of magnitude to the efficiency of simple pressure and pressure-swirl atomizers for a comparable droplet size. The efficiency declines with both the pressure and GLR with approximately logarithmic tendency.
\end{abstract}

Keywords: Twin-fluid atomization; Effervescent atomization; Atomization efficiency; Energy conversion; Two-phase flow.

\section{Abbreviations $^{2}$}

\section{Nomenclature}

Roman characters

A interfacial area

$\left(\mathrm{m}^{2}\right)$

a specific expansion work

$c$ constant in the bubbly flow

$D$ diameter

$D_{20}$ surface area mean diameter

$D_{32}$ Sauter mean diameter

$\bar{D}$ mean diameter

E energy

$e$ energy, represented as percentages of the total input energy, specific energy $(\%,-)$

GLR gas-to-liquid ratio by mass $(\%,-)$

$g$ gravitational acceleration

$\left(\mathrm{m} / \mathrm{s}^{2}\right)$

$h$ specific enthalpy

ID integral diameter - diameter averaged through entire radial profile or cross-section

\footnotetext{
* Corresponding author: jedelsky@fme.vutbr.cz, tel: +420 541143266

${ }^{2}$ Gas-to-liquid ratio (GLR), Homogeneous Flow Model (HFM), Light heating oil (LHO), Phase-Doppler anemometry (PDA), Separated Flow Model (SFM).
} 


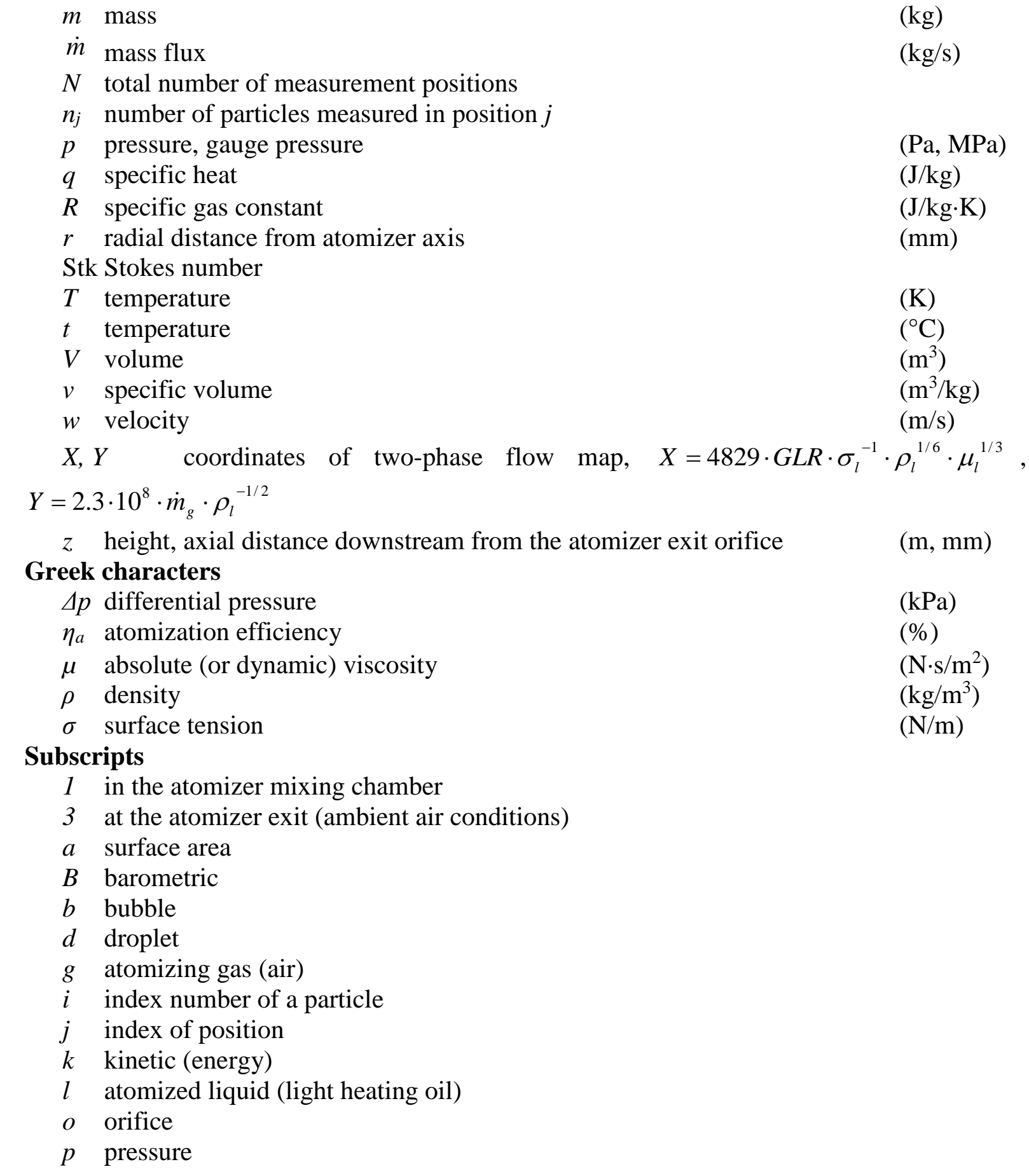

\section{Introduction}

Effervescent atomizers, though relatively new spraying devices, have already been used in a number of practical applications, such as combustion of heavy and waste liquids [1-4], coalwater slurries [5, 6], in gas turbine engines [7], internal combustion engines [8], scramjet engines [9], for spray drying [10], spray coating [11, 12], in process industries [13, 14], for fire suppression $[15,16]$ and others. The main purpose of atomizers in all these applications is to transform the bulk liquid into fragments or small droplets. This process consumes energy but there are also other important energy-related effects to be considered when designing or choosing an atomizer; e.g. transport of the liquid to a target position at the required droplet velocity, impact and air entrainment. Other requirements, that do not demand energy directly (such as the size distribution/uniformity of droplets, spray steadiness, dispersion of liquid to 
certain required area, transverse mixing and desired spray cone angle), are energy consuming as well or restricts the choice to a less efficient atomizer designs. The breakup mechanism and spray development in the effervescent atomization have been intensively studied in the past two decades however a deeper insight into the atomization process and its energy transfer is important for continuing advancement of the atomization performance.

Recent legislation requirements in transport industry led to dramatic increase in diesel injection pressure (typically 200 - $250 \mathrm{MPa}[17,18]$ ) to produce sufficiently fine sprays using common pressure injectors. At such pressures, material strength limits are reached and fuel pumps consume considerable portion of the engine power. Designers are therefore looking for other atomization techniques with lower energy consumption and a potential for further droplet size reduction as seen in [19].

Conversion effectiveness of the input energy into the increased surface tension energy of the atomized liquid can be quantified by the atomization efficiency, $\eta_{a}$, which is a property of rather optimistic estimates by the vast community. Knowledge of the atomization efficiency is useful for comparison of different types of atomizers and it also enables optimization of atomizer operation conditions for the required spray quality. Understanding the energy transfer helps figure out the basic principles of the atomization process. Information on atomization efficiency of different atomizers can be found in the book by Bayvel and Orzechowski [20]. The efficiency of atomization for all traditionally used atomizers is very small, namely $\eta_{a}<0.1 \%$, and any spray quality improvement demands disproportionally more energy due to a drop in the atomization efficiency. For example, pressure atomizers that generate droplets with a diameter of $100 \mu \mathrm{m}$ work with $\eta_{a}=0.05-0.07 \%$ and, in the case of a diameter of 50 $\mu \mathrm{m}$, the efficiency drops to the order of several thousandths of a per cent. Pressure atomizers have commonly higher atomization efficiency than pneumatic atomizers [20]. Pneumatic (alias twin-fluid or two-fluid [21]) atomizers use gas to support the atomization process; different forms of these atomizers utilize the gas energy in different ways [22, 23].

Petela [24] introduced an exergetic approach into atomization process of liquid and applied it to the pressure and airblast (pneumatic) atomization. He found the exergetic efficiency of the pressure atomization be below $1 \%$ and decrease with the growth in the inlet pressure. The exergetic efficiency of the airblast atomization was found dependent on the gas-to-liquid ratio by mass (GLR) with the maximum of $0.038 \%$ for GLR $=50 \%$; steeply declining for decreasing GLR and gradually declining with growing GLR.

Effervescent atomizers, as a subclass of the internally mixing twin-fluid atomizers, are generally supposed to work with the atomization efficiency superior to their fellows, however the statement that atomization efficiency of effervescent atomizers is substantially higher than the efficiencies of pressure, rotary, and most types of twin-fluid atomizers [25] seems to be too optimistic and it is in contrast with [20].

Low energy consumption of effervescent atomizers was recognised already by Chawla [5] in slurry spraying. Several other papers [5, 22, 26, 27] deal with energy considerations of the effervescent atomization but no systematic study was dedicated to a detailed description of the energy conversion process of effervescent atomization, and no direct comparison of atomization efficiency of different atomizer types was found. In this paper, we address the issue of energy transfer processes during the internal flow, discharge and formation of an effervescent spray.

\section{Methodology}

The qualitative (phenomenological) explanation of mechanisms involved in the atomization process is based on experimental visualization of the internal two-phase flow and the spray. Our photographic and thermographic flow visualization is supplemented with data from a two-phase flow map published, and supported with available literature data. The ener- 
gy balance is explained generally using a simple physical equation derived from the law of energy conservation. Quantitative values of individual energy terms are based on the test data of a measured effervescent atomizer, and on results of spray measurement by means of phaseDoppler anemometry (PDA).

Our team, in the long term, focuses on effervescent atomization of light heating oil (LHO) using air as the atomizing medium. In our earlier work [1], a systematic study of 18 singlehole, plain-orifice atomizers of type A was performed. Atomizer E34, with geometry and dimensions given in Fig. 1, was chosen as a good representative of that atomizer class for the present study. The gas injection configuration of the atomizer is "outside-in", where liquid (LHO) enters the central tube axially and the air penetrates into the liquid through a set of small holes. The atomizer was operated continuously under cold (non-reacting) conditions. Atomization characteristics were studied using PDA at atomizing pressures, $p_{1}$, of $0.1,0.3$ and $0.5 \mathrm{MPa}$ and GLR of 2, 5 and 10\%. A detailed description of the atomizer design, test results, experimental setup and droplet size measurement can be found in [1]. The working principle of the atomizer is shown in Fig. 2.

Infrared thermography was applied to determine the temperature field in the effervescent spray. Infrared camera Jenoptic - VarioCam with the resolution $320 \times 240$ pixels and a standard lens $\left(32^{\circ} \mathrm{H} \times 25^{\circ} \mathrm{V}\right)$ monitored the spray with temperature homogeneous background at $19.7^{\circ} \mathrm{C}$ from a distance of $500 \mathrm{~mm}$. The temperature of LHO at the nozzle inlet was $19^{\circ} \mathrm{C}$. The near nozzle spray structure was visualized using macro photography. The spray was illuminated with the use of an external flash with exposure time 1/50,000 s and documented by digital camera CANON EOS 300D employing telephoto zoom lens CANON EF 100mm. Several different operation regimes of the atomizer were documented.

\section{Results and discussion}

First, a description of the energy transfer during a general atomization process is given followed by an explanation of the energy terms essential for pneumatic atomization. Numerical values valid for effervescent atomization are given based on our experimental data. The processes during the internal flow, discharge and formation of an effervescent spray are analysed and followed by an introduction of the atomization efficiency as important characteristics of the atomization process.

\subsection{General energy considerations and energy ratios of effervescent atomization}

Atomization of liquids is a complex energy conversion process accompanied with transformation of energy amongst several energy types. A general energy equation for steady onedimensional homogeneous equilibrium flow without mass and energy accumulation at a point inside an atomizer can be written as:

$$
d q+d e+d h+\frac{d w^{2}}{2}+g d z-v d p+\sigma d a=0
$$

where $q$ is heat transfer (e.g. heat energy input to preheat high-viscosity liquids [4] or to preheat liquids for supercritical or flash-boiling atomization, etc.), $e$ is a general symbol for any other input energy source required for a given atomization device (e.g. electric energy for ultrasonic and electrostatic atomizers, mechanical power for rotary atomizers), $h$ is the mixture enthalpy (it changes when the mixture is heated/cooled by an external source, friction losses, expansion cooling, evaporation/condensation of volatile liquids depending on environment state and discharge features, when steam is used as the atomizing gas etc.), $g$ is the gravitational acceleration and the term $-v \cdot d p$ (a decompression of pressurized atomizing gas during the discharge or the momentum transfer to the surrounding atmosphere accompanied by flow deceleration) is related to the input pressure energy and it also represents the expansion work) 
and the last term characterises a variation of the surface area of the liquid. The equation is written for a unit mass of the fluid (liquid or gas-liquid mixture).

Eq. (1) is applicable to most of the atomizer types. The potential energy term $(g \cdot d z)$ may be neglected in majority of the atomization techniques. In twin-fluid atomization (airblast, effervescent, Y-jet and others), the pressure energy is required to pump liquid and to pressurize atomizing gas while the terms $d q$ and $d e$ are often irrelevant.

A phenomenological description of the energy transfer and methodology for evaluation of atomization efficiency will be explained on the example of an effervescent atomizer depicted in Figs. 1 and 2. Information required for the description is based on our work in combination with findings of other investigators. Numerical data for estimation of the individual energy terms are taken from [1] (for a set of atomizers studied there); particular data for atomizer E34 (Fig. 1) are used where needed. LHO is a non-evaporating/non-condensing medium and the original surface tension energy of the bulk liquid is negligible. Adiabatic flow conditions are considered during the internal flow, discharge and spraying.

Energy ratios of effervescent atomization are documented in Table 1 for several values of inlet parameters, namely pressure and GLR and their combination. The individual energy forms are represented as percentages of the total input energy, which is the sum of the energy to pressurize the gas and to pump the liquid. The input energy of the compressed gas relative to the total input energy, $e_{p g 1}$, increases with GLR from $88 \%$ at GLR $=0.01$ to $99 \%$ at $\mathrm{GLR}=0.1$. Contrary, the input energy to pump the liquid $e_{p l 1}$, decreases at all pressures as a function of GLR from about $11 \%$ to $1 \%$ for GLR $=0.01$ and 0.1 , respectively. Both forms of the input energy are partially transformed into the kinetic energy and into the surface tension energy of the internal two-phase flow. The relative kinetic energy of the mixture inside the mixing chamber $e_{k 1}$, with its maximum about $0.03 \%$ for the inlet gauge pressure $p_{1}=0.1 \mathrm{MPa}$ and GLR $=0.01$, is negligible. The same applies to the relative surface tension energy of bubbles/foam inside the mixing chamber, $e_{a 1}$, which is in fraction of a percent and decreases with pressure.

Fundamental part of the input pressure energy (both gas and liquid) is converted into kinetic energy of the two-phase mixture discharged. Note that although the input energy to pressurize gas is by one order of magnitude greater than the input energy to pump the liquid, the kinetic energy of the gas in the discharged two-phase mixture, $e_{\mathrm{kg}}$ is, on the contrary, by two orders lower than the kinetic energy of the discharged liquid $e_{k l 3}$. The kinetic energy of the discharged two-phase mixture is then partially transferred to the momentum of the surrounding gas [28], into expansion work when the gas expands out of the atomizer, and some part also remains with the moving dispersed gas-droplet flow.

The kinetic energy of the discharged two-phase mixture, i.e. spray, namely its liquid and gaseous parts, is calculated according to Eqs. (2) and (3) for the data acquired from PDA measurements of atomizer E34 [1] in the axial distance of $100 \mathrm{~mm}$ from the exit orifice. The remaining kinetic energy at this distance is already very low. The relative energy of the flowing gas $e_{\mathrm{kg}}$ is only $0.05 \%$ of the total input energy at $p_{1}=0.5 \mathrm{MPa}$ and GLR $=10 \%$. It increases with GLR and with the inlet pressure. The relative energy of moving droplets $e_{k l 3}$ shows the opposite tendency with its maximum values in units of per cents at low pressures and low GLRs. Only a small fraction of the total input energy is transferred to the increase of the droplet surface area, which is the parameter that describes the atomization process quality. The relative surface tension energy of droplets $\left(e_{a 3}=\eta_{a}=\right.$ atomization efficiency, addressed in section 3.4.) depends on pressure and GLR, and has a maximum of $0.14 \%$ for $p_{1}=0.1 \mathrm{MPa}$ and GLR $=1 \%$. Larger part of the input energy goes to expansion work of the gas, $a_{3}$, which is about $20-30 \%$, depending on the inlet pressure. Most of the input energy ends up converted to turbulent internal/external flow and mixing of the viscous two-phase fluid, shear and 
frictional losses on passage walls, losses during choked discharge, and momentum transferred to the surrounding atmosphere.

The kinetic energy of the discharged mixture can be estimated separately for the gas and liquid phase using the PDA data. The gas kinetic energy per mass unit is:

$$
e_{k g 3}=\frac{E_{k g 3}}{m}=\frac{0.5}{1+1 / G L R} \sum_{j=1}^{N} r_{j} w_{g j}^{3} / \sum_{j=1}^{N} r_{j} w_{z g j}
$$

where $r_{j}$ is the radial distance from atomizer axis and $w_{g j}$ is the mean gas velocity at position $j$. Constant gas density, axially symmetrical spray and equidistant sampling distance $\Delta r_{j}=r_{j}-r_{j}$ 1 are supposed. The gas velocity is calculated as $w_{g j}=\frac{1}{n_{j}} \sum_{i=1}^{n_{j}} w_{d i j}$, using values of the individual droplet velocity $w_{d i}$ as an estimate of the gas velocity; only droplets with Stokes number Stk $<<1$ (that can be assumed to perfectly follow the flow field) are included. The kinetic energy of liquid (droplets) per unit mass is:

$$
e_{k l 3}=\frac{E_{k l 3}}{m}=\frac{0.5}{1+G L R} \sum_{j=1}^{N} r_{j} \sum_{i=1}^{n_{j}} D_{i j}^{3} w_{d i j}^{2} / \sum_{j=1}^{N} r_{j} \sum_{i=1}^{n_{j}} D_{i j}^{3}
$$

where $D_{i j}$ is the diameter of individual droplet $i$ at position $j$, and $w_{d i j}$ is its velocity.

\subsection{Fluid mixing and internal two-phase transport}

The atomization process starts with introducing gas into the liquid inside the mixing chamber. The interaction between the gas and liquid differs depending on GLR and, moderately, also on the inlet pressure as seen in the Baker's map for the vertical flow [29] (Fig. 3). The mixing chamber is not long enough to allow the flow to fully develop, however the map can give an insight into the flow character. Qualitatively different mixtures form at low GLR and at high GLR [30]. A bubbly flow, present at low GLR, changes to slug, churn, annular and finally to the dispersed flow with GLR increase. A flow regime significantly influences the breakup process and resulting spray.

At low GLR, the gas enters the liquid at low velocity. The slowly flowing liquid acts on the penetrating gas and when the drag force overcomes the surface tension, $\sigma$, the gas bulk is teared off forming a bubble. The bubble size depends on surface tension, fluid densities and their velocities [30, 31]. The entry gas velocity is governed by the size of the aeration holes and operation conditions. The liquid velocity prior to mixing depends on the ratio of crosssections of the mixing channel and exit orifice, and on the operation conditions. It is also the geometric arrangement of the aerator that influences the two-phase formation. The bubbles can agglomerate or breakup during the flow [30], though Huang et al. [32] observed a relatively steady bubbly flow with only few bubbles coalescing. Their chaotic - turbulent motion towards the exit orifice promotes mixture homogeneity, however gas-liquid separation can appear for horizontal flows [33]. The bubbles shape depends on their size. Small bubbles tend to reach spherical shape while larger bubbles elongate and warp due to pressure fluctuations in the turbulent flow. The bubbly flow can develop only if:

$$
G L R \leq c \frac{\rho_{g 1}}{\rho_{l}}=c \frac{p_{g 1}+p_{B}}{\rho_{l} R T}
$$

where $\rho_{g 1}$ and $\rho_{l}$ are gas and liquid densities, respectively, $p_{g 1}$ is the gas gauge pressure upstream the exit orifice, $R$ is the specific gas constant and $T$ is the temperature of the mixture. The constant $c$ depends on the structure of the bubbly flow. A mixture containing spherical 
monodisperse bubbles uniformly arranged in a simple cubic pattern results in $c=\pi /(6-\pi)$. The bubbly flow regime for the most effective geometrical configuration of monodisperse bubbles shows $c=2.85$ or for polydisperse bubbles $c=4.6$ according Lefebvre [22]. The bubbly flow limits calculated for the last $c$ value fit the best with experimental results of Huang et al. [32]. The use of LHO physical properties (from Table 1, footnote f) and air at room temperature in Eq. (4) leads to GLR $\leq 6.2 p_{g 1}[\%, \mathrm{MPa}]$. Note that for fully developed flow of pure liquids, the bubbly flow conditions are fulfilled if the void fraction is lower than about 10\% [34]; the void fraction for real bubbly flow observed in [32] and predicted by Eq. (4) for $c=4.6$ (polydisperse bubbles) is much greater than $10 \%$, which suggests the flow cannot develop fully. Larger and more numerous bubbles form as the amount of gas increases. The bubbles can eventually reach the size of the channel diameter. Such slug flow, characterised with intermittent discharge of dominant fraction of one phase, causes an undesired fluctuating spray [33]. Further increase in the gas amount leads to an increase in the flow velocity; the mixture is frothy or churn and it is more homogeneous than in the previous case. Continuing in the increase in the gas fraction, the flow becomes annular, i.e. all liquid flows on the channel wall while gas occupies the central area of the channel. The fast flowing gas acts upon the slowly flowing liquid, waving its surface and eventually also forming droplets. The interfacial area $A_{1}$ increases with GLR for bubbly flow, with the bubble surface tension energy per unit mass of the mixture, $m$ :

$$
e_{a 1}=\frac{E_{a 1}}{m}=\frac{\sigma A_{1}}{m}=\frac{6 \sigma}{\rho_{g 1} \overline{D_{1}}} \frac{G L R}{(G L R+1)}
$$

where the average bubble size is equal to the surface area mean diameter of the bubbles: $\overline{D_{1}}=D_{b 20}$. The situation is more complicated for slug and churn flows, and for the annular flow this area reduces with GLR because of a simple cylindrical interface between the gas and liquid.

The mixing process is, in the simplest case of equal inlet temperatures of the gas and liquid, practically isothermal. The inlet gas gauge pressure, $p_{g 1}$, differs from the liquid gauge pressure, $p_{l 1}$, only to allow the gas to flow through aeration holes; the pressure difference $\Delta p_{1}=p_{g 1}-p_{l 1}$ is typically in $\mathrm{kPa}$ order [33]. The energy associated with the pressure difference transforms into heat due to friction losses and into surface tension energy of the mixture. A small pressure difference along the mixing channel is needed to overcome wall friction and resistance at the turbulent motion of the two-phase mixture. These effects consume only a small fraction of the input energy. However, the mixture formation is very important for the resulting spray quality; the size of produced droplets is proportional to the square root of the initial thickness or diameter of the ligaments from which they were formed [35].

\subsection{Two-phase discharge and liquid breakup}

The mixture accelerates due to cross-section reduction (Bernoulli principle) which leads to bubble elongation [26, 36] and expansion controlled by the pressure drop (Fig. 2). It causes further increase in interfacial surface; liquid membranes, filaments and ligaments are formed [37]. This phase corresponds well to the film formation in the case of prefilming atomizers or pressure-swirl atomizers although it is managed differently. Gas bubbles expand and finally explode $[9,38]$ causing ligament thinning and disruption. The gas flows with greater velocity than the liquid (choked flow if critical pressure ratio achieved [1]) and acts on the liquid ligaments in a similar way as in the case of airblast prefilming atomization. This velocity slip results in the acceleration of the liquid mass followed with subsequent transformation of the bulk liquid into shreds and ligaments, and with a surface wave formation, which enhances the 
atomization process. The gas-liquid interaction influences the liquid instability in the nearnozzle region. The drag between both phases causes a small decrease in the air velocity [39].

At very low GLR, about $0.1 \%$, and low pressure $0.01 \mathrm{MPa}$, the liquid forms a continuous film as well as ligaments at the nozzle exit (Fig. 4). The thin ligaments disintegrate due to surface tension and wrap into droplets. The primary breakup takes place over a distance of several nozzle diameters. Increasing GLR promotes disintegration of the liquid volumes and shortens the breakup distance. At GLR $>2 \%$, no compact liquid volume is observed; the twophase mass already in the vicinity of the exit orifice contains a cloud of small particles too optically dense to look through, however we assume that also at higher GLR a liquid core also exists at higher GLR at the nozzle exit as documented by ballistic imaging [38]. The atomization process, in the case of annular or dispersed internal two-phase flow, relies on the aerodynamic shear force.

The gas-liquid mixture is spatially homogeneous only in the case of low GLR, where bubbly flow forms. A relatively constant mean droplet size within the radial profile is seen in this case [40, 41]. As for the slug and annular regime, the mixture is more heterogeneous [42]. In this case, the gas occupies mainly the inner part of the flow channel whereas the liquid is attached to the channel walls due to adhesive forces. This uneven gas distribution means that the gas pressure energy is concentrated near the exit orifice centreline where it enhances the breakup process while the atomization out of the centreline suffers from the lack of the gas leading to larger droplets [36]. Radial profile of droplet size with a distinct minimum near the spray centreline and maximums at the spray borders, as observed in [1, 43], results from this phenomena.

The intensity in the momentum transfer between the gas and liquid inside the exit hole can be estimated by comparing real discharge characteristics with predictions by analytical models of two-phase discharge. This comparison was made for a set of 26 single-hole effervescent atomizers with "outside-in" gas injection operating with LHO at pressures ranging between 0.1 and $1 \mathrm{MPa}$, and GLR between 0.01 and 1 [1]; the real discharge coefficient was found to be just in the middle of two extreme cases of gas-liquid discharge (1) without slip between the gas and liquid phases (Homogeneous Flow Model = HFM) and (2) with maximum slip between the phases (Separated Flow Model = SFM) irrespective of the pressure and GLR.

The velocity slip between the gas and liquid phase, which is very small for bubbly flow and large for annular flow inside the mixing chamber, increases in the constricted exit orifice. The gas accelerates and reaches the highest speed in the smallest cross-section for non-choked conditions or near behind it for choked conditions. The momentum transfer between gas and liquid accelerates the liquid; small liquid fragments reach greater velocity than large filaments oriented mostly parallel to the flow. The expanding gas decelerates with the distance from the exit orifice. The formed droplets keep the momentum of the parent liquid fragments, so in large distances from the orifice, large droplets are faster than the surrounding air while the velocity of small droplets, decelerated due to drag force, corresponds to the air velocity. Mixing with the surrounding air also decelerates the spray. The discharge process thus leads to an interesting spatially variable velocity distribution of the gas and liquid, where positive or negative correlation between the velocity and the droplet size appears, depending on radial and axial distances from the nozzle exit. Even a non-monotonous tendency can appear as seen in Fig. 5. The trajectory of large particles follows well the direction given during discharge. The motion of small particles is dictated by the turbulent gas flow which leads to their dispersion and enhances transversal mixing [44]. It results in a twin-peak size distribution in large radial distances, as seen in [45], and also contributes to droplet collisions and coalescence.

The interfacial area of droplets, $A_{3}$, increases with GLR in the bubbly flow regime, with the bubble surface tension energy per unit mass of the mixture, $m$ : 


$$
e_{a 3}=\frac{E_{a 3}}{m}=\frac{\sigma A_{3}}{m}=\frac{6 \sigma}{\rho_{l} \overline{D_{3}}} \frac{1}{(G L R+1)}
$$

where the average droplet size is equal to the surface area mean diameter of the droplets: $\overline{D_{3}}=D_{d 20}$. For a ratio between the surface tension energy of final droplets and surface tension energy of the bubbles in the internal flow using Eq. (5) and Eq. (6) we obtain: $\frac{e_{a 3}}{e_{a 1}}=\frac{\rho_{g 1}}{\rho_{l}} \frac{D_{b 20}}{D_{d 20}} \frac{1}{G L R} \approx \frac{p_{g 1}+p_{B}}{G L R}$. This ratio denotes how many times the surface tension energy increases during external processes. It is in the order of magnitude of 10 for GLR $=0.01$.

Expansion cooling during discharge causes the temperature of the liquid to drop down; but several centigrades only (Fig. 6). It is due to a high specific heat capacity of the liquid compared to that of the gas. A very fast discharge, however, does not allow for intense heat transfer and cooling of the liquid by the expanding gas. Note that the infrared camera performs a "temperature averaging" over the spray thickness so it gives an approximate image of the temperature distribution. The lowest temperature is achieved near the nozzle exit with consequent temperature relaxation as the surface temperature propagates through the droplet volume.

\subsection{Atomization efficiency}

The atomization efficiency is given by the ratio of the surface tension energy of droplets in the spray, $E_{a 3}$, to the total energy $E_{1}$ required to produce the spray, $\eta_{a}=E_{a 3} / E_{1}$. The term $E_{1}$ in twin-fluid atomization is the sum of the energy introduced by the pressurized gas, $E_{g 1}$, and the energy of the supplied liquid, $E_{11}[5,19,26]$. The isothermal compression energy (the minimum necessary compression energy) needed to pressurize the gas mass $m_{g}$ from the atmospheric pressure $p_{B}$ to the pressure $p_{g 1}+p_{B}$ in front of the nozzle reads:

$$
E_{g 1}=\frac{m_{g}}{\rho_{g 1}} \cdot\left(p_{g 1}+p_{B}\right) \cdot \ln \left(\frac{p_{g 1}+p_{B}}{p_{B}}\right)=V_{g 1} \cdot\left(p_{g 1}+p_{B}\right) \cdot \ln \left(\frac{p_{g 1}+p_{B}}{p_{B}}\right)
$$

where $\rho_{g 1}$ and $V_{g 1}$ are the density and the volume of the pressurized gas, respectively. The potential energy of the supplied liquid reads:

$$
E_{l 1}=p_{l 1} \cdot m_{l} / \rho_{l}=p_{l 1} \cdot V_{l} .
$$

Using Eqs. (7) and (8) and defining the equation for GLR as:

$$
G L R=m_{g} / m_{l}=\left(V_{g 1} \cdot \rho_{g 1}\right) /\left(V_{l} \cdot \rho_{l}\right)
$$

we can write:

$$
E_{1}=E_{g 1}+E_{l 1}=V_{l} \cdot\left[p_{l 1}+G L R \cdot \frac{\rho_{l}}{\rho_{g 1}} \cdot\left(p_{g 1}+p_{B}\right) \cdot \ln \left(\frac{p_{g 1}+p_{B}}{p_{B}}\right)\right] .
$$

Transformation of bulk liquid into fine droplets is associated with enormous increase of surface area. The area of the droplet system after fragmentation of bulk liquid with volume $V_{l}$ will be $A_{3}=6 \cdot V_{l} / I D_{20}$. The diameter $I D_{20}$ (so called Integral surface area mean diameter) is a virtual diameter which all droplets in the spray would have if their number and total surface area agreed with the ones found in the actual spray. It can be estimated using PDA data as 
$I D_{20}=\left(\sum_{j=1}^{N} r_{j} \sum_{i=1}^{n_{j}} D_{i j}^{2} / \sum_{j=1}^{N} r_{j} n_{j}\right)^{1 / 2}$, where $n_{j}$ is the number of particles measured in the radial distance $r_{j}$. The corresponding increase in the surface tension energy (neglecting the original surface tension energy of bulk liquid) reads $E_{a 3}=A_{3} \cdot \sigma$ [46]. The atomization efficiency is thus:

$$
\eta_{a}=\frac{E_{a 3}}{E_{1}}=\frac{6 \cdot V_{l} \cdot \sigma / I D_{20}}{E_{1}}=\frac{6 \cdot \sigma / I D_{20}}{p_{l 1}+G L R \cdot \frac{\rho_{l}}{\rho_{g 1}} \cdot\left(p_{g 1}+p_{B}\right) \cdot \ln \left(\frac{p_{g 1}+p_{B}}{p_{B}}\right)} .
$$

The efficiency of effervescent atomization, shown in Fig. 7 left, for varying inlet pressure and GLR, is less than $0.5 \%$ for the studied range of operation regimes. As suggested by the loglog scale of the plot, there is approximately an inverse logarithmic tendency of the $\eta_{a}$ with GLR, and a similar trend was also found for pressure. In many applications, such as for example mass and heat transfer, fuel combustion or catalysis, the Sauter mean diameter, $D_{32}$, is of higher importance than the surface area diameter, $D_{20}$. The atomization efficiency is for several atomizer types plotted against $D_{32}$, in Fig. 7 right. The increase in the pressure and GLR promotes the atomization hence reducing $D_{32}$, as well as $D_{20}$. However the atomization efficiency drops down which means the input gas and liquid energies are utilized less effectively. Note that a similar behaviour was found for the airblast atomizers [27], and explained by increased gas-liquid separation which reduces the fraction of gas that participates on the breakup process. Our findings prove the Lefebvre's suggestions to operate effervescent atomizers at the bubbly flow regime in order to lower the gas consumption.

Fig. 7 right shows that the efficiency $\eta_{a}$ for effervescent atomizers is lower than the efficiency $\eta_{a}$ for pressure atomizers which is in accordance with [20]. It also follows from Fig. 7 left when extrapolating to GLR $\rightarrow 0$ (purely pressure atomizers). It disagrees with the statement about superior $\eta_{a}$ of an effervescent injector compared to a conventional pressure injector in [19]. This discrepancy could be, however, caused by very different operation conditions in our and that case; an effervescent atomizer operated at the inlet pressure in the order of $100 \mathrm{kPa}$ was compared with pressure atomizers at $1 \mathrm{MPa}$ in our case, and an effervescent injector operated at the injection pressure 12.2 - 28.9 MPa was compared with a pressure injector at $150 \mathrm{MPa}$ in the work [19]. The atomization efficiency of effervescent atomizers generally decreases when smaller droplets are required (fig. 7 right); atomization at elevated pressures and low GLRs produces a spray of the same quality more effectively than the atomization at the inverse combination of pressure and GLR. Note that the requirement of small droplets in pressure atomization, which is related to the atomization pressure growth, also leads to a drop in atomization efficiency, consistently with [24].

Fig. 8 documents the ratio of the inlet pressure of pressure atomization to the inlet pressure of effervescent atomization required for the same input energy. It was calculated using Eq. (10) which was applied to both atomization techniques. The ratio strongly varies with GLR with negligible effect of pressure when $p_{1} / \mathrm{GLR}<700$ [MPa, \%]. For greater $p_{1} / \mathrm{GLR}$, the input energy of the liquid for effervescent atomization reaches the same magnitude as the input energy of the compressed gas, and the pressure ratio drops down with an increase in inlet pressure, approaching asymptotically unity for $p_{1} / \mathrm{GLR}>10^{6}$. Considering the efficiency of effervescent atomization to be about 10 times lower compared to pressure atomization (an estimation made from Fig. 7 right for comparable flow rates), we can see from Fig. 8 that the inlet pressures for the effervescent atomization are about 10 times lower than the inlet pressures for the pressure atomization for the same droplet size at GLR $=10 \%$ and $p_{1}<1 \mathrm{MPa}$ (typical operation conditions of our low-pressure effervescent nozzles). 
Regardless of the worse efficiency of the effervescent atomization compared to the pressure one, its main advantage can be seen in the possibility to acquire the spray of the same quality at much lower pressure. A larger clear area of the exit orifice of the effervescent atomizers protects them from clogging and makes them especially useful for waste liquids. Moreover, they generate droplets of given size with higher efficiency than the other types of twinfluid atomizers, and particularly the airblast ones [47].

\section{Summary and conclusions}

This work considers effervescent atomization as an energy conversion process which starts with gas injection into the liquid, and results in a fully developed spray. Mechanisms involved in the two-phase mixture formation during the internal flow, discharge and spray formation were qualitatively described based on authors' experimental results and available literature data.

The estimation of the energy balance for effervescent atomization shows that the gasliquid surface formation process during internal mixing as well as discharge consumes a minor part of the input energy. Most of the input energy is spent on the expansion work of the discharged gas, the air entrainment process and losses related to the two-phase flow and the discharge. The atomization efficiency is in the order of tenths of percent for inlet pressures range $0.1-1 \mathrm{MPa}$ and GLR $0.2-10 \%$. It depends on operation conditions of the atomizer and declines with the increase in GLR and with the increase in the inlet pressure. It was found out to be always lower than the efficiency of pressure atomizers for comparable conditions.

A future work could focus on comparison of diverse twin-fluid atomizer types. We assume that differences in their internal design affects the breakup mechanism and consequently the atomization efficiency.

\section{Acknowledgements}

Authors greatly acknowledge financial support from project No. 101/11/1264 funded by the Czech Grant Agency.

\section{References}

[1] Jedelsky J, Jicha M, Slama J, Otahal J. Development of an Effervescent Atomizer for Industrial Burners. Energy \& Fuels 2009;23:6121-30.

[2] Buckner HN, Sojka PE, Lefebvre AH. Effervescent atomization of coal-water slurries. ASME Publ., 1990; pp. 105-8.

[3] Loebker D, Empie HJ, Tappi. Effervescent spraying: A new approach to spraying high solids black liquor. TAPPI International Engineering Conference. Miami, Fl, 1998; pp. 157-67.

[4] Kermes V, Belohradsky P. Experimental study on combustion of liquid renewable fuels. Pres 2010: 13th International Conference on Process Integration, Modelling and Optimisation for Energy Saving and Pollution Reduction 2010;21:457-62.

[5] Chawla JM. Atomization of Liquids Employing the Low Sonic Velocity in Liquid/Gas Mixtures. Proceedings of the Third ICLASS-85, 1985; pp. LP/1A/5/1-LP/A/5/7.

[6] Daviault SG, Ramadan OB, Matida EA, Hughes PM, Hughes R. Atomization performance of petroleum coke and coal water slurries from a twin fluid atomizer. Fuel 2012;98:183-93.

[7] Lefebvre AH, Wang XF, Martin CA. SPRAY CHARACTERISTICS OF AERATED-LIQUID PRESSURE ATOMIZERS. Journal of Propulsion and Power 1988;4:293-8.

[8] Wade RA, Weerts JM, Sojka PE, Gore JP, Eckerle WA. Effervescent atomization at injection pressures in the MPa range. Atomization and Sprays 1999;9:651-67.

[9] Gadgil HP, Raghunandan BN. Some features of spray breakup in effervescent atomizers. Experiments in Fluids 2011;50:329-38.

[10] Mujumdar AS, Huang LX, Chen XD. An overview of the recent advances in spray-drying. Dairy Science \& Technology 2010;90:211-24.

[11] Esfarjani SA, Dolatabadi A. A 3D simulation of two-phase flow in an effervescent atomizer for suspension plasma spray. Surface \& Coatings Technology 2009;203:2074-80. 
[12] Qian LJ, Lin JZ, Xiong HB. Modeling of non-Newtonian suspension plasma spraying in an inductively coupled plasma torch. International Journal of Thermal Sciences 2011;50:1417-27.

[13] Loebker D, Empie HJ. High mass flow-rate effervescent spraying of high viscosity Newtonian liquid. the 10th Annual Conference on Liquid Atomization and Spray Systems. Ottawa, ON, 1997; pp. 253-7.

[14] Qian LJ, Lin JZ, Xiong HB. Numerical Modeling in Radio Frequency Suspension Plasma Spray of Zirconia Powders. Plasma Chemistry and Plasma Processing 2010;30:733-60.

[15] Huang X, Wang XS, Liao GX. Characterization of an effervescent atomization water mist nozzle and its fire suppression tests. Proceedings of the Combustion Institute 2011;33:2573-9.

[16] Lal S, Kushari A, Gupta M, Kapoor JC, Maji S. Experimental study of an air assisted mist generator. Experimental Thermal and Fluid Science 2010;34:1029-35.

[17] Delacourt E, Desmet B, Besson B. Characterisation of very high pressure diesel sprays using digital imaging techniques. Fuel 2005;84:859-67.

[18] Wang XG, Huang ZH, Kuti OA, Zhang W, Nishida K. Experimental and analytical study on biodiesel and diesel spray characteristics under ultra-high injection pressure. International Journal of Heat and Fluid Flow 2010;31:659-66.

[19] Sovani SD, Crofts JD, Sojka PE, Gore JP, Eckerle WA. Structure and steady-state spray performance of an effervescent diesel injector. Fuel 2005;84:1503-14.

[20] Bayvel L, Orzechowski Z. Liquid Atomization: Taylor \& Francis Inc., 1993.

[21] Gretzinger J, Marshall WR. CHARACTERISTICS OF PNEUMATIC ATOMIZATION. Aiche Journal 1961;7:312-8.

[22] Lefebvre AH. TWIN-FLUID ATOMIZATION: FACTORS INFLUENCING MEAN DROP SIZE. Atomization and Sprays 1992:101-19.

[23] Chin JS. EFFERVESCENT ATOMIZATION AND INTERNAL MIXING AIR ASSIST ATOMIZATION. International Journal of Turbo \& Jet-Engines 1995;12:119-27.

[24] Petela R. EXERGETIC ANALYSIS OF ATOMIZATION PROCESS OF LIQUID. Fuel 1984;63:41922.

[25] Sovani SD, Sojka PE, Lefebvre AH. Effervescent atomization. Progress in Energy and Combustion Science 2001;27:483-521.

[26] Lörcher M, Schmidt F, Mewes D. Flow Field and Phase Distribution Inside Effervescent Atomizers. 9th ICLASS 2003, 2003; pp. 12-9.

[27] Lefebvre AH. ENERGY CONSIDERATIONS IN TWIN-FLUID ATOMIZATION. Journal of Engineering for Gas Turbines and Power-Transactions of the Asme 1992;114:89-96.

[28] Bush SG, P. E. Sojka. Entrainment by Effervescent Sprays at Low Mass Flowrates. Proc of the 6th ICLASS, 1994; pp. 609-15.

[29] Process Associates of America. Modified Baker's map for horizontal two-phase flow with transformed coordinates. Available at: http://www.processassociates.com/process/fluid/2faz xy.htm Acessed March 2003.

[30] Shepard TG. Bubble Size Effect on Effervescent Atomization. THE FACULTY OF THE GRADUATE SCHOOL OF THE UNIVERSITY OF MINNESOTA. MINNESOTA: THE UNIVERSITY OF MINNESOTA, 2011; p. 149.

[31] Lefebvre AH. Some recent developments in twin-fluid atomization. Particle \& Particle Systems Characterization 1996;13:205-16.

[32] Huang X, Wang X, Liao G. Visualization of two phase flow inside an effervescent atomizer. Journal of Visualization 2008;11:299-308.

[33] Jedelsky J, Jicha M. Characteristics of a Two-Phase Flow Inside the Mixing Chamber of an Effervescent Atomizer. International Symposium on Two-Phase Flow Modelling and Experimentation. Pisa, Italy, 2004.

[34] Wallis G. One Dimensional Two-Phase Flow: Mcgraw-Hill (Tx), August 1969.

[35] Lefebvre AH. Atomization and Sprays. Bristol: Tailor \& Francis, 1989.

[36] Ramamurthi K, Sarkar UK, Raghunandan BN. Performance characteristics of effervescent atomizer in different flow regimes. Atomization and Sprays 2009;19:41-56.

[37] Santangelo PJ, Sojka PE. A HOLOGRAPHIC INVESTIGATION OF THE NEAR-NOZZLE STRUCTURE OF AN EFFERVESCENT ATOMIZER-PRODUCED SPRAY. Atomization and Sprays 1995;5:137-55.

[38] Linne M, Sedarsky D, Meyer T, Gord J, Carter C. Ballistic imaging in the near-field of an effervescent spray. Experiments in Fluids 2010;49:911-23.

[39] Shavit U. Gas-liquid interaction in the liquid breakup region of twin-fluid atomization. Experiments in Fluids 2001;31:550-7.

[40] Li J, Lefebvre AH, Rollbuhler JR. Effervescent atomizers for small gas turbines. American Society of Mechanical Engineers, 1994; pp. 1-6. 
[41] Kufferath A, Wende B, Leuckel W. Influence of liquid flow conditions on spray characteristics of internal-mixing twin-fluid atomizers. International Journal of Heat and Fluid Flow 1999;20:513-9.

[42] Catlin CA, Swithenbank J. Physical processes influencing effervescent atomizer performance in the slug and annular flow regimes. Atomization and Sprays 2001;11:575-95.

[43] Kushari A. Effect of injector geometry on the performance of an internally mixed liquid atomizer. Fuel Processing Technology 2010;91:1650-4.

[44] Luong JTK, Sojka PE. Unsteadiness in effervescent sprays. Atomization and Sprays 1999;9:87-109.

[45] Jedelsky J, Jicha M, Slama J. Characteristics and Behaviour of Multi-Hole Effervescent Atomizers. Proc ILASS-Europe 2004. Nottingham, United Kingdom, 2004; pp. 521-6.

[46] Frohn A, Roth N. Dynamics Of Droplets. Berlin: Springer-Verlag, 2000.

[47] Sher E, Elata C. SPRAY FORMATION FROM PRESSURE CANS BY FLASHING. Industrial \& Engineering Chemistry Process Design and Development 1977;16:237-42.

[48] Jedelsky J, Jicha M. Unsteadiness in effervescent sprays: A new evaluation method and the influence of operational conditions. Atomization and Sprays 2008;18:49-83.

[49] Jagannathan TK, Nagarajan R, Ramamurthi K. Effect of ultrasound on bubble breakup within the mixing chamber of an effervescent atomizer. Chemical Engineering and Processing 2011;50:305-15.

[50] Durdina L, Jedelsky J, Jicha M. Spray structure of a pressure-swirl atomizer for combustion applications. EPJ Web of Conferences 2012;25:01010. 


\section{Table}

Table 1 Energy balance for effervescent atomization, atomizer E34 (Fig. 1) operated with $\mathrm{LHO}^{\mathrm{f}}$ and air.

\begin{tabular}{|c|c|c|c|c|c|c|c|c|c|}
\hline $\begin{array}{c}p_{1} \\
\mathrm{MPa}\end{array}$ & $\begin{array}{c}\text { GLR } \\
-\end{array}$ & $\begin{array}{c}e_{p g 1}{ }^{\mathrm{a}} \\
\%\end{array}$ & $\begin{array}{c}e_{p l 1}{ }^{\mathrm{a}} \\
\%\end{array}$ & $\begin{array}{c}e_{k 1} \mathrm{~b} \\
\%\end{array}$ & $\begin{array}{c}e_{a 1}{ }^{\mathrm{c}} \\
\%\end{array}$ & $\begin{array}{c}e_{k g 3}{ }^{\mathrm{d}} \\
\%\end{array}$ & $\begin{array}{c}e_{k l 3}{ }^{\mathrm{d}} \\
\%\end{array}$ & $\begin{array}{c}e_{a 3}{ }^{\mathrm{d}} \\
\%\end{array}$ & $\begin{array}{c}a_{3}{ }^{\mathrm{e}} \\
\%\end{array}$ \\
\hline 0.1 & 0.01 & 88.4 & 11.6 & 0.030 & 0.0111 & - & - & - & 30.5 \\
\hline 0.1 & 0.02 & 93.9 & 6.1 & 0.031 & 0,0117 & 0.012 & 1.229 & 0.249 & 32.0 \\
\hline 0.1 & 0.05 & 97.4 & 2.6 & 0.027 & - & 0.026 & 0.509 & 0.116 & 32.3 \\
\hline 0.1 & 0.1 & 98.7 & 1.3 & 0.021 & - & 0.033 & 0.222 & 0.059 & 31.2 \\
\hline 0.3 & 0.01 & 88.4 & 11.6 & 0.015 & 0.0028 & - & - & - & 30.2 \\
\hline 0.3 & 0.02 & 93.9 & 6.1 & 0.012 & 0.0029 & 0.035 & 1.025 & 0.121 & 31.8 \\
\hline 0.3 & 0.05 & 97.4 & 2.6 & 0.009 & - & 0.040 & 0.381 & 0.057 & 32.0 \\
\hline 0.3 & 0.1 & 98.7 & 1.3 & 0.006 & - & 0.035 & 0.185 & 0.032 & 31.0 \\
\hline 0.5 & 0.01 & 88.4 & 11.6 & 0.009 & 0.0012 & - & - & - & 25.9 \\
\hline 0.5 & 0.02 & 93.9 & 6.1 & 0.007 & 0.0013 & 0.041 & 0.854 & 0.088 & 27.3 \\
\hline 0.5 & 0.05 & 97.4 & 2.6 & 0.004 & 0,0013 & 0.048 & 0.374 & 0.048 & 27.5 \\
\hline 0.5 & 0.1 & 98.7 & 1.3 & 0.003 & - & 0.052 & 0.194 & 0.028 & 26.6 \\
\hline
\end{tabular}

\footnotetext{
a based on the data measured, and calculated according Eqs. (7-10)

b calculated using a discharge model proposed in [1]

c calculated for bubbly flow using Eq. (5), bubble diameter $D_{b 1}=3.5 \mathrm{~mm}$ (average value from $[9,48,49]$ )

d based on PDA results in spray, calculated according Eqs. $(2,3,11)$

e calculated for isothermal expansion, energy transfer to the liquid and surrounded air is not taken into account

f physical properties of LHO: density $\rho_{l}=874 \mathrm{~kg} / \mathrm{m}^{3}$, liquid/gas surface tension $\sigma=0.0297 \mathrm{~kg} / \mathrm{s}^{2}$
} 


\section{Figure captions}

Fig. 1. Effervescent atomizer with main dimensions. All dimensions are in millimetres.

Fig. 2. Schematic layout of an effervescent atomizer with nomenclature and illustration of the mixing/atomization processes. Not to scale.

Fig. 3. Modified Baker's map for vertical downward two-phase flow with transformed coordinates according to [21] with marked influence of operational conditions on the two-phase flow regime. Arrows show direction of regime change while the appropriate values increase. AB-SP: line defining transition between bubble and plug or annular and slug pattern, A-BF: annular/bubble-froth pattern transition, A-D: annular/dispersed pattern transition. The results are calculated for air/LHO mixture.

Fig. 4. Spray structure of an effervescent atomizer at varying inlet pressure and GLR.

Fig. 5. Size-velocity correlation, $p_{1}=0.3 \mathrm{MPa}$, GLR $=2 \%$, radial distance $r=0 \mathrm{~mm}$, axial distance $z=100 \mathrm{~mm}$ from exit orifice.

Fig. 6. Thermographic snapshot of the effervescent spray with the Celsius scale, $p_{1}=0.3 \mathrm{MPa}, \mathrm{GLR}=10 \%$.

Fig. 7. (left) Atomization efficiency of effervescent atomizer at various operation pressure and GLR. (right) Atomization efficiency of different atomizer types with regard to produced $I D_{32}$ : e - effervescent atomizer with orifice diameter $D_{o}=2.5 \mathrm{~mm}$, operated with LHO/air; PS pressure-swirl atomizer with $D_{o}=2.8 \mathrm{~mm}$, LHO; PD - simplex atomizer with $D_{o}=0.4 \mathrm{~mm}$, LHO; P1 - new design of pressure-swirl atomizer with $D_{o}=0.36 \mathrm{~mm}$, Kerosene; P2 - old design of pressure-swirl atomizer with $D_{o}=0.36 \mathrm{~mm}$, Kerosene [50].

Fig. 8. Ratio of atomization pressures, atomization of LHO using air, $p_{B}=98 \mathrm{kPa}$, $t_{1}=t_{3}=20^{\circ} \mathrm{C}$, air considered as an ideal gas. The abscissa indicates an inlet pressure of the pressure atomization. 


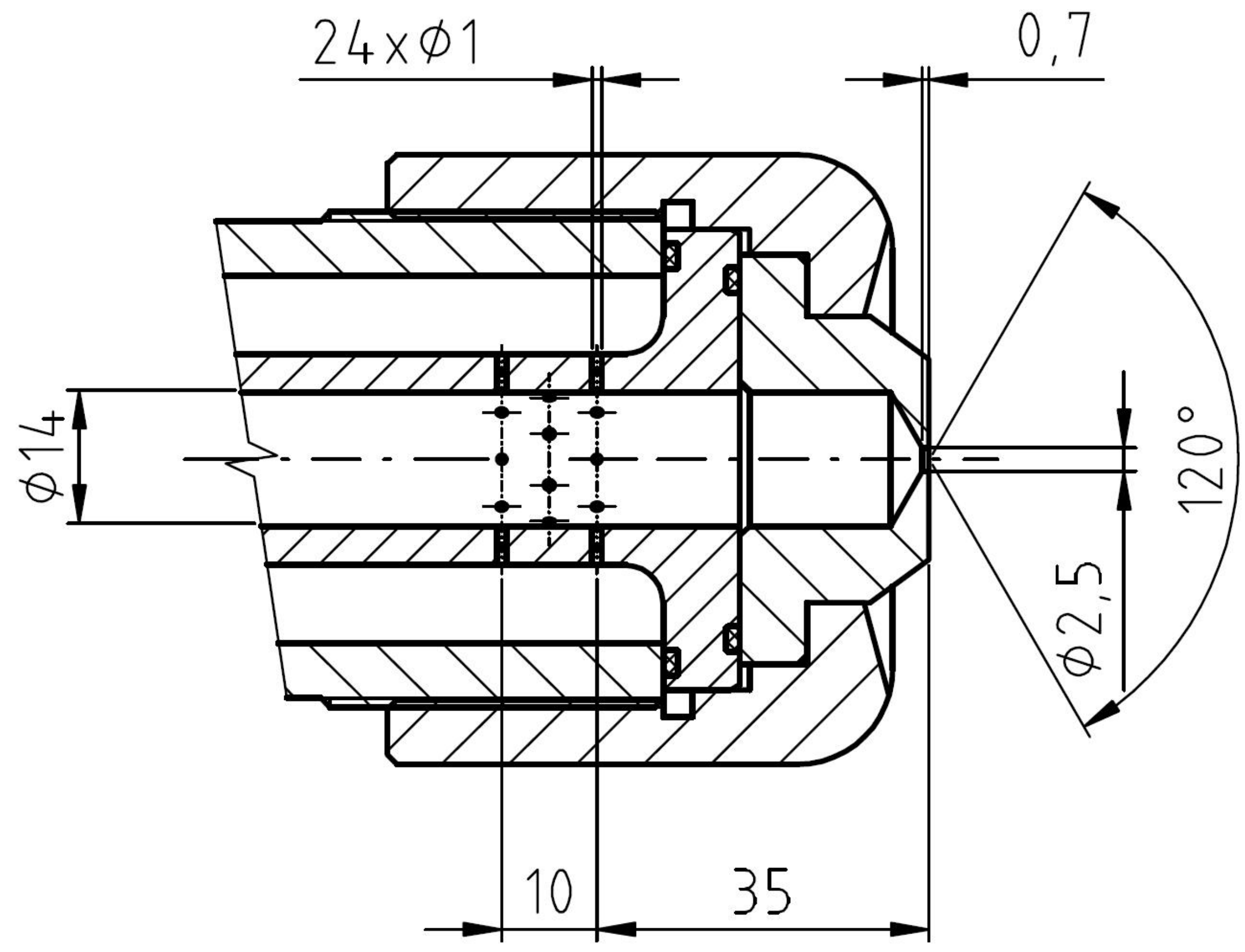




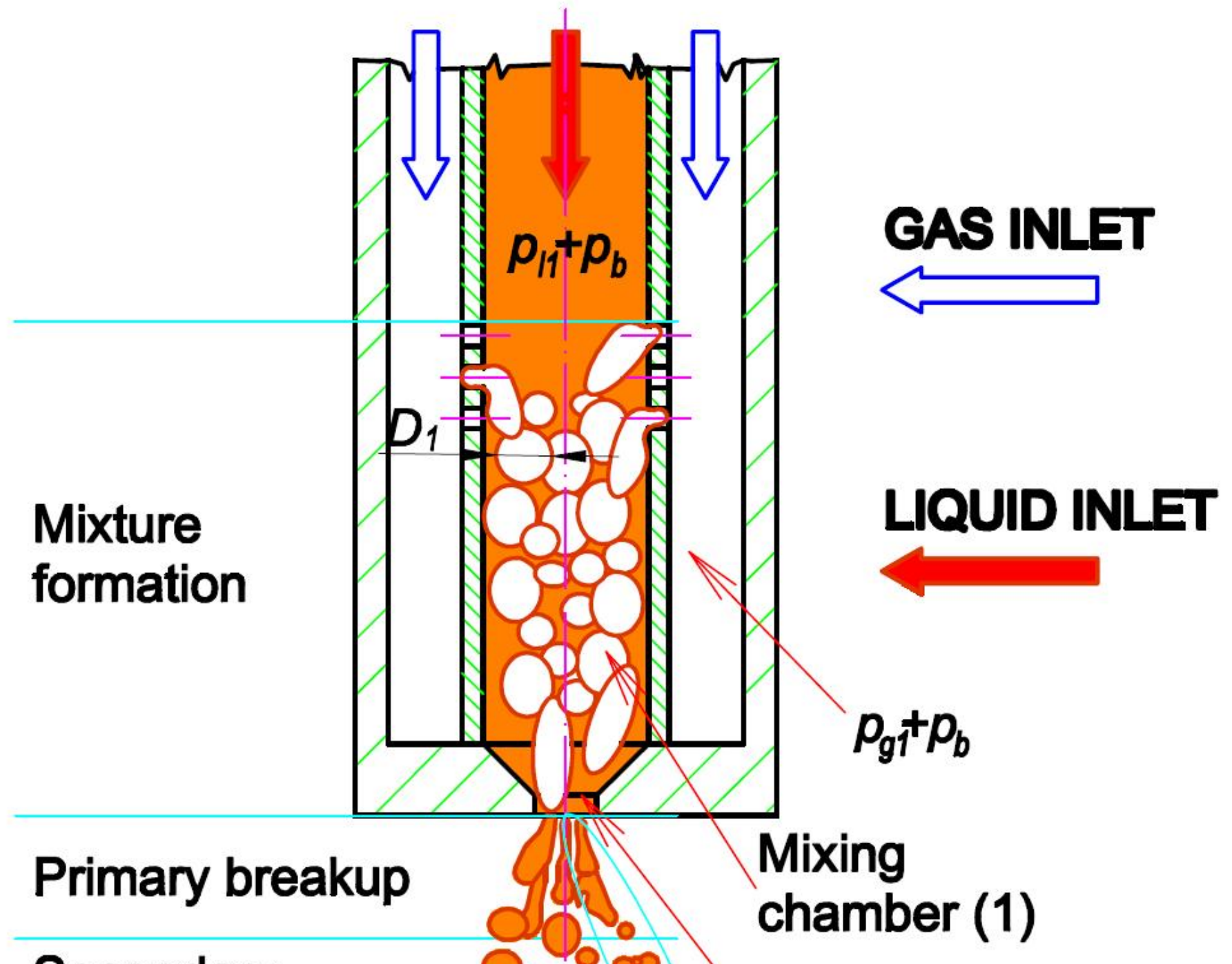

Secondary

breakup

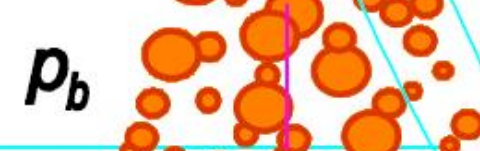

Discharge orifice (2)

Fully developed spray

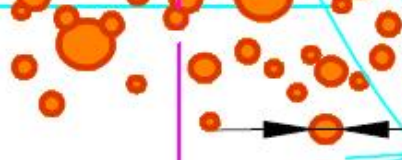

Ambient

Mixing with ambient air atmosphere (3) 


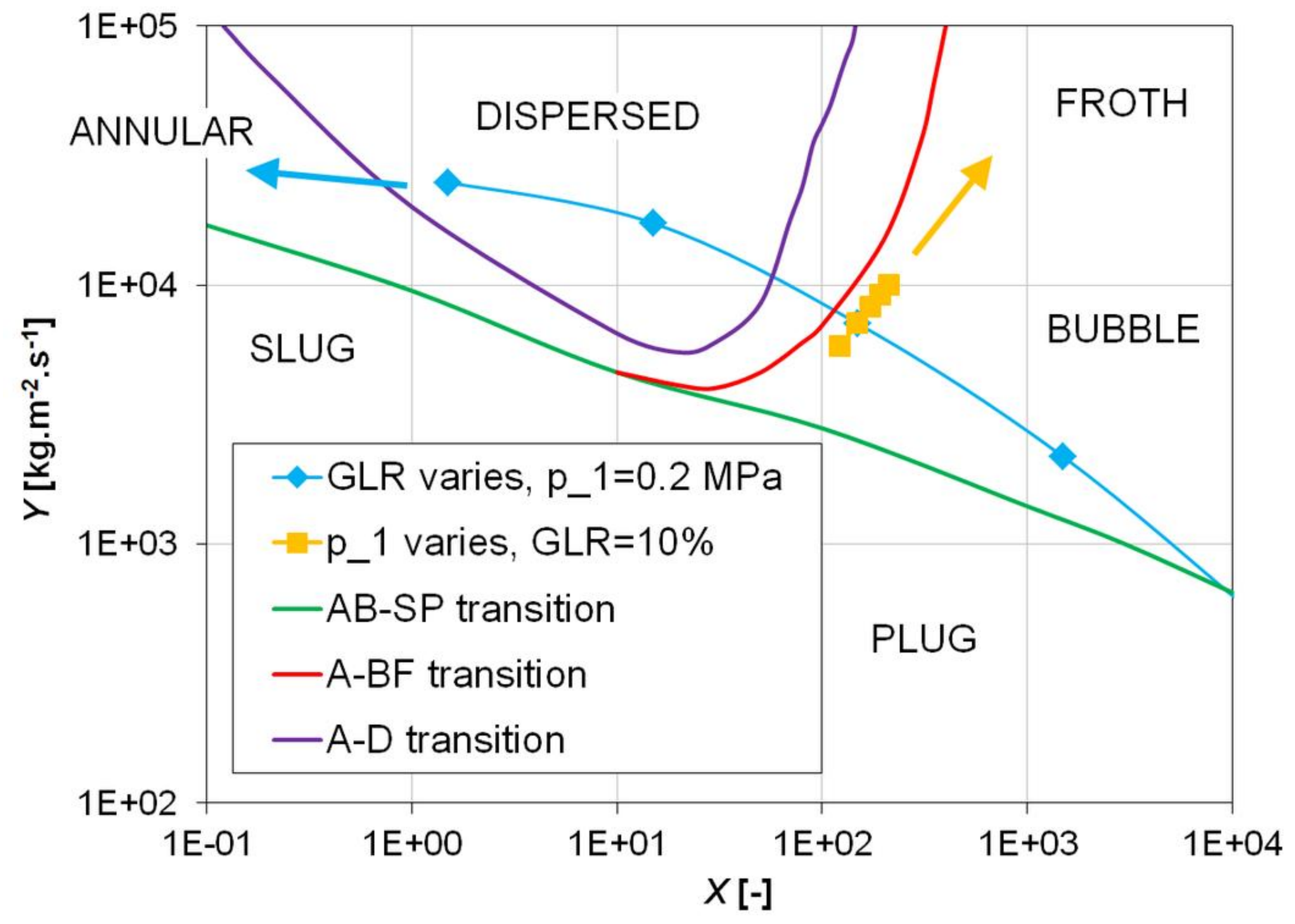




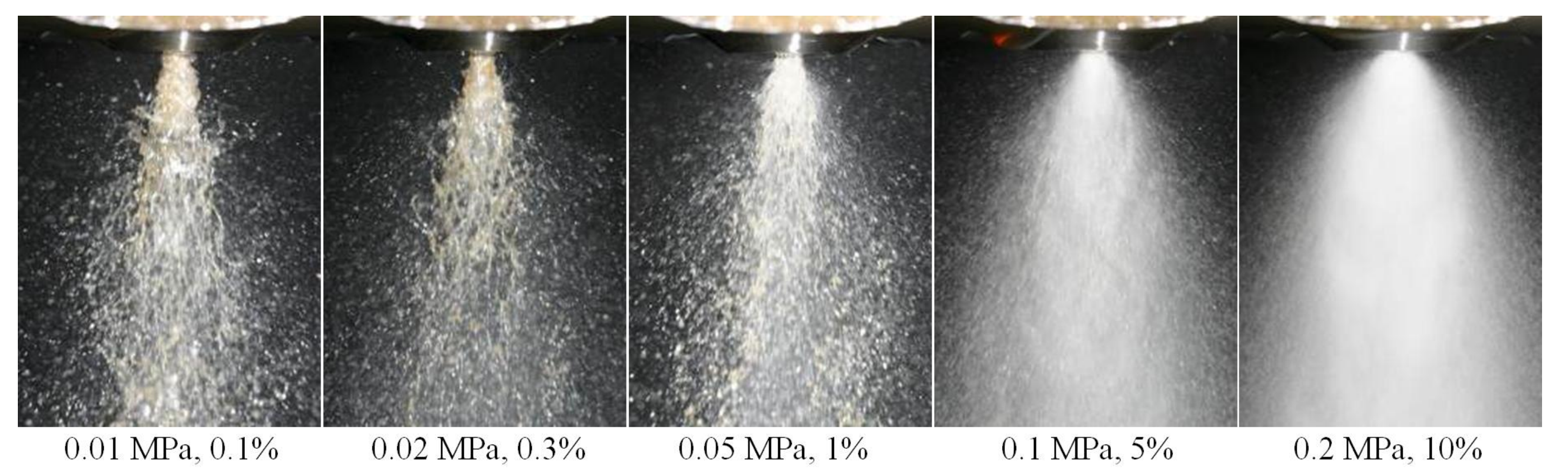




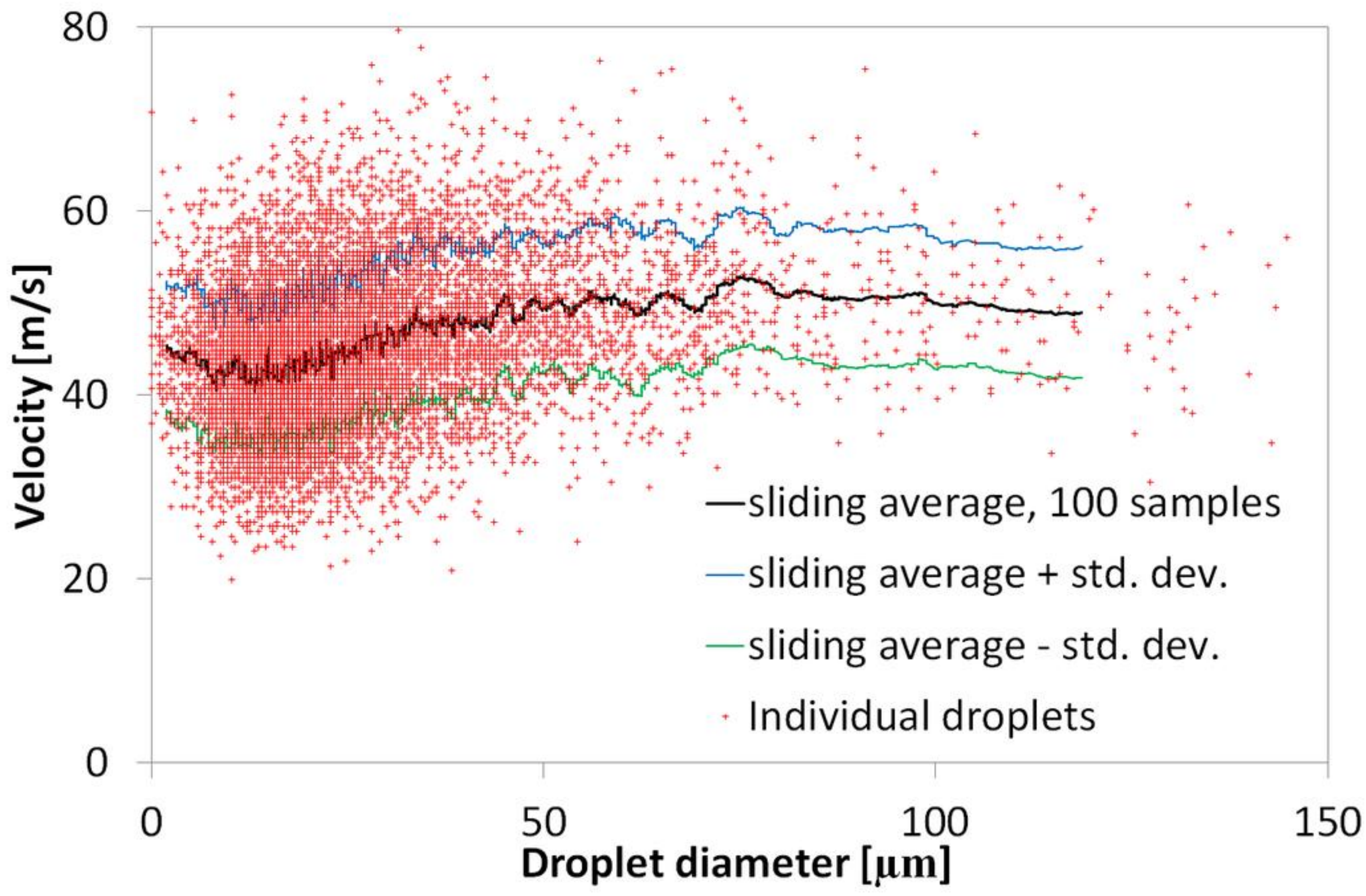



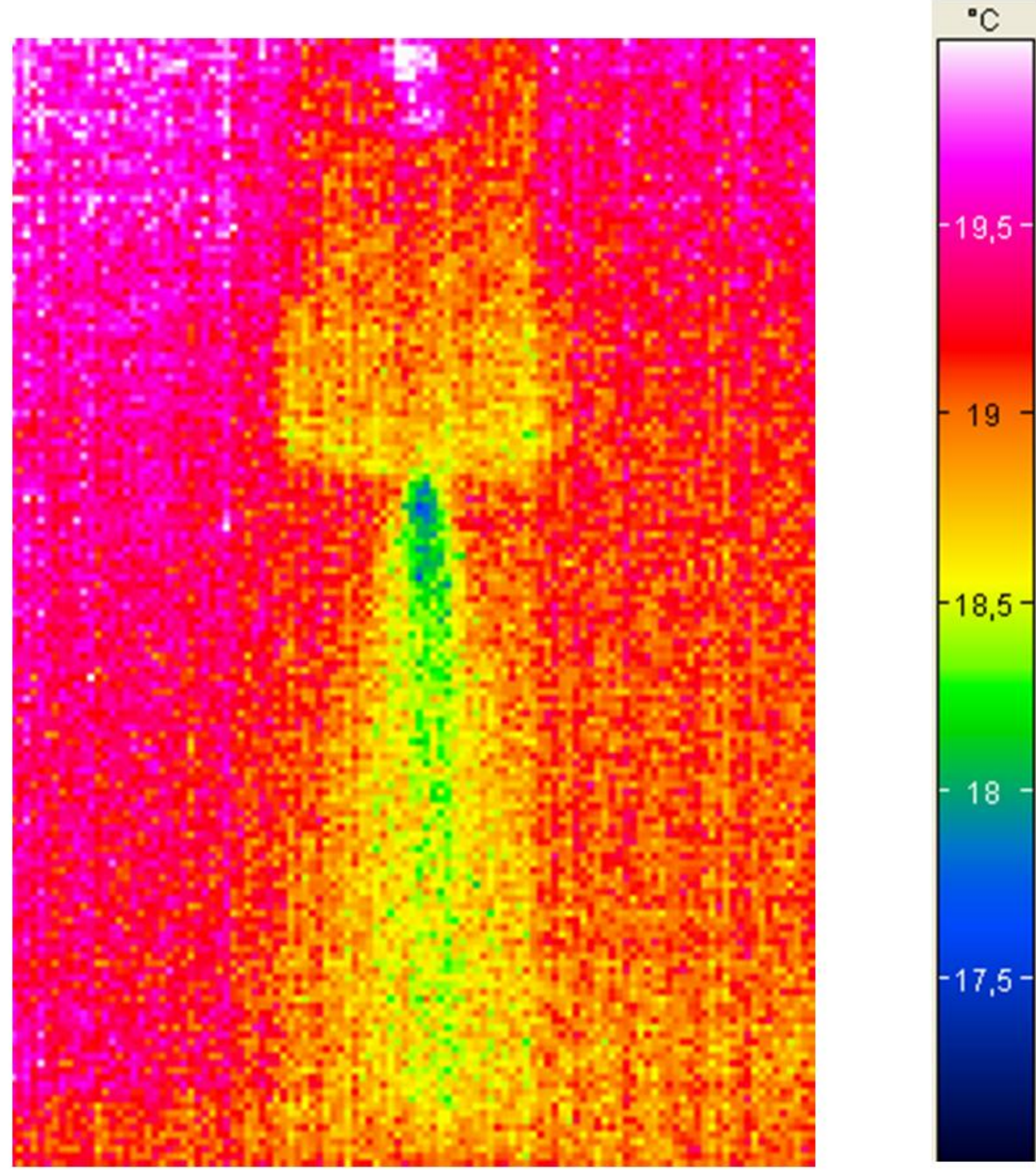


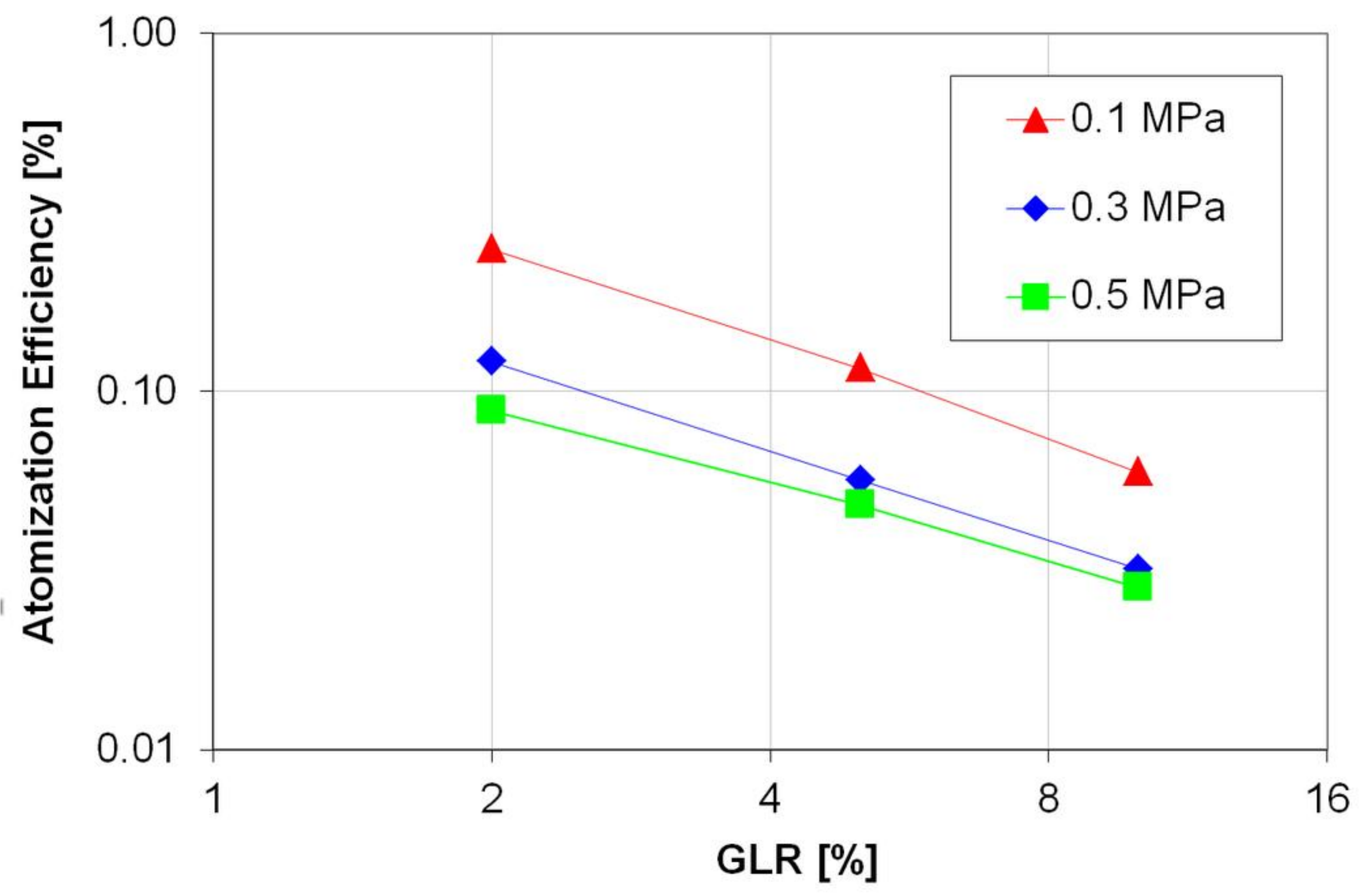




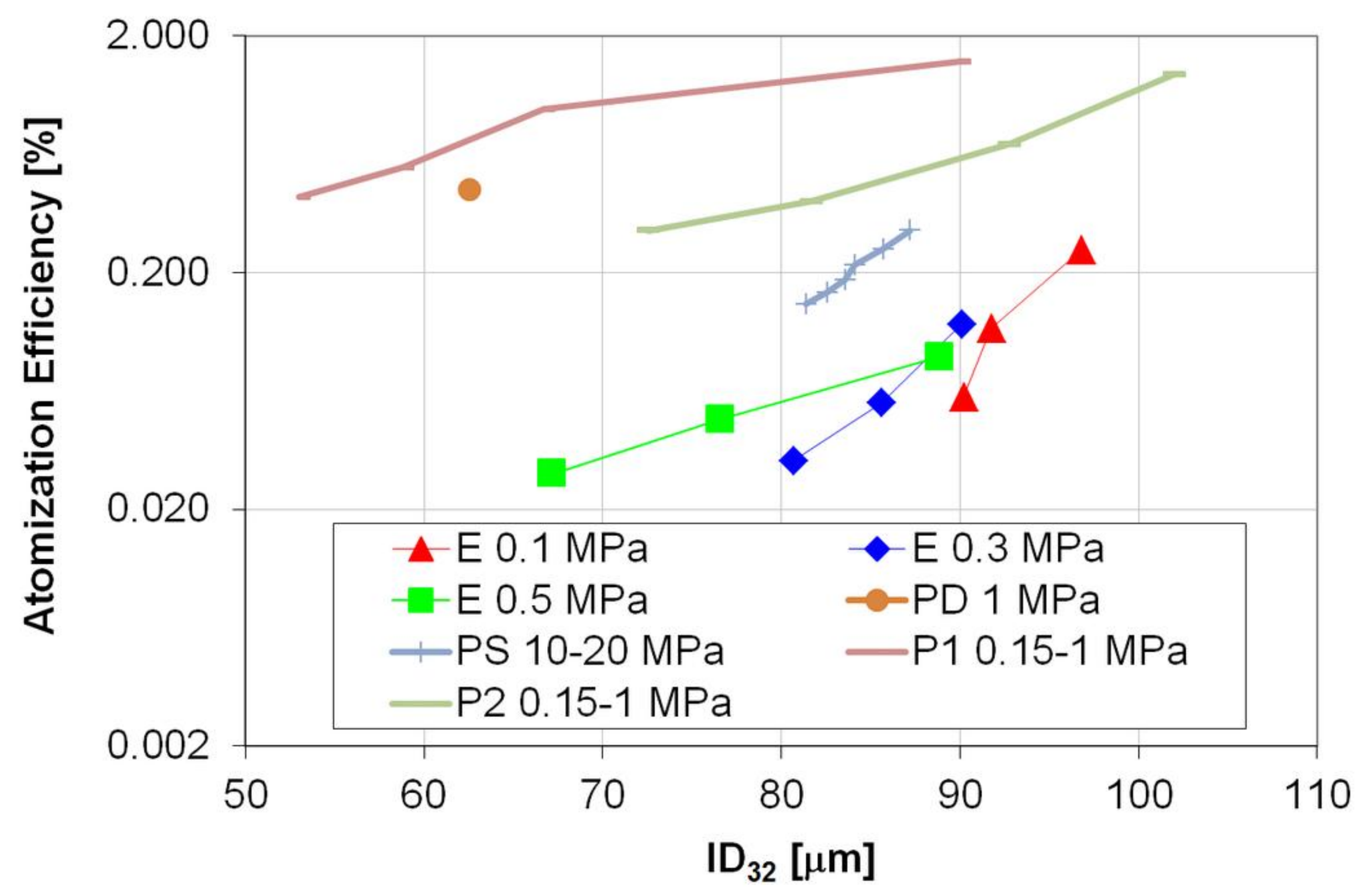




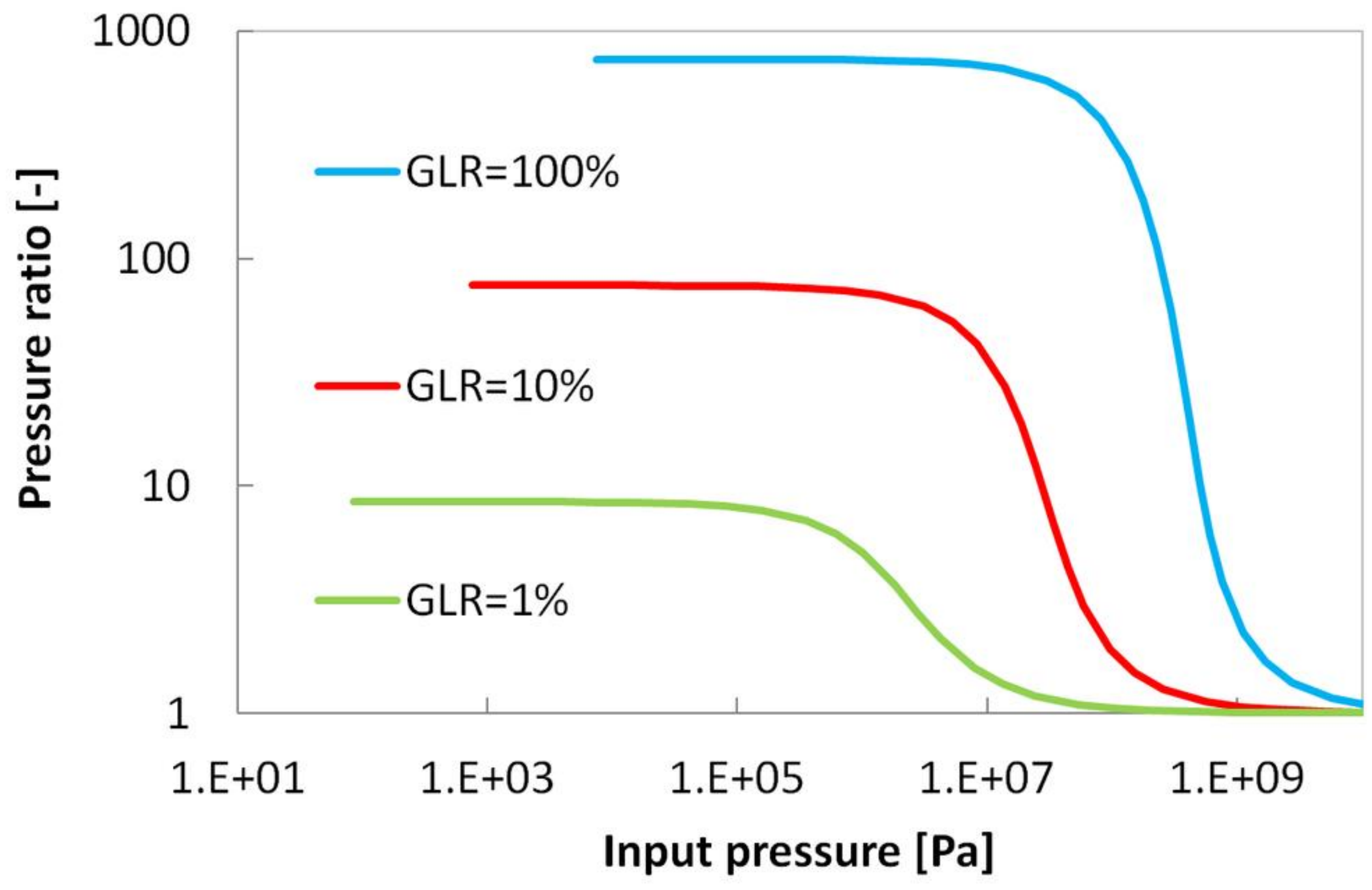

